\title{
Hydroalcoholic Extract from Copaifera Langsdorffii Has Skin Wound Healing Activity in Rats
}

\begin{abstract}
The loss of skin integrity causes wounds, and in response, the organism promotes the healing process, which is divided into three phases: inflammatory, proliferative and remodeling. Several plant species have been tested in healing experimental wounds due to popular application. Among the species used in skin wound healing related in popular knowledge is Copaifera langsdorffii. By this way, we aim to analyze wound healing changes in rats with skin lesions after treatment with hydroalcoholic extract from Copaifera langsdorffii leaves. Male Wistar rats were submitted to excisional injury with a $2 \mathrm{~cm}$ diameter in the dorsal region. They were divided into groups $(n=6)$ with daily treatments of hydroalcoholic extract at $1 ; 5$ and $10 \%$ concentrations or a negative control (saline) during 3, 7 and 21 days. The lesions were analyzed and measured daily. Blood was collected for toxicity analysis, and dorsal lesions were collected for histological analysis and measurements of cellularity in normal skin, border and center of the lesion. The toxicity data did not show any significant differences between the groups. Microscopic analysis showed an increase in total cell number at the edges of the extract treated groups after 3 days. Macroscopically, the groups treated with $5 \%$ and $10 \%$ extract demonstrated better wound retraction compared with saline treatment. In summary, the groups treated with hydroalcoholic extract of Copaifera langsdorffii showed the efficacy of the plant as treatment of skin wound healing.
\end{abstract}

Keywords: Copaifera langsdorffii; Ethnopharmacology; Skin; Wound healing

Research Article
Volume 6 Issue 1 - 2017
Lucas F S Gushiken ${ }^{1}$, Carlos A Hussni'
Jairo K. Bastos ${ }^{3}$, Ariane L Rozza ${ }^{1}$, Carlos R
Padovani ${ }^{4}$, Regina K Talkahira ${ }^{5}$ and Cláu dia
H Pellizzon ${ }^{1 *}$
${ }^{1}$ Morphology Department/UNESP, Institute of Biosciences of
Botucatu, Brazil
${ }^{2}$ Department of Surgery and Veterinary Anesthesiology/
UNESP, School of Veterinary Medicine and Animal Science,
Brazil
${ }^{3}$ Department of Pharmaceutical Sciences, University of São
Paulo, Brazil
${ }^{4}$ Department of Biostatistics, Institute of Biosciences of
Botucatu, Brazil
${ }^{5}$ Department of Veterinary Clinic/ UNESP, School of Veterinary
Medicine and Animal Science, Brazil
*Corresponding author: Cláudia Helena Pellizzon,
Morphology Department, Institute of Biosciences of
Botucatu, Unesp, P.O. Box 510, Zip Code 18618-970,
Botucatu/SP, Brazil, Tel: 00 55 014 3880 0463;
Email: claudia@@ibb.unesp.br
Received: November 02, 2016 | Published: March 21, 2017

Abbreviations: ALT: Alanine Aminotransferase; AST: Aspartate Aminotransferase; EH: Hydroalcoholic Extract of Copaifera Langsdorffii Leaves; HE: Hematoxylin And Eosin; HPLC: High Performance Liquid Chromatography; NMR: Nuclear Magnetic Resonance; SD: Standard Deviation; $\gamma \mathrm{GT}$ : Gamma Glutamyl Transferase

\section{Introduction}

The skin is the largest organ of the body and a barrier that covers the body's surface [1]. One of its main functions is to protect vertebrates in all environments, including exposure to antigens, chemical and physical protection against external agents, body thermoregulation, control of entry and exit of electrolytes and protection against water loss. In addition, the skin has many nerve endings that are responsible for receiving environmental information and sending them to the central nervous system $[2,3]$. The loss of skin integrity causes wounds that can be caused by a variety of events, such as trauma, exposure to heat, cold, corrosive materials, radiation or impaired blood circulation [4]. In response to these insults, the body promotes the healing process, a dynamic process that restores the function and integrity of damaged tissue [2].

All stages of the healing mechanisms are dependent on cellular, molecular and physiological processes for the structural restoration of the damaged region. Due to the high complexity of this cascade of events, some authors use didactic classifications to separate the phases of wound healing $[5,6]$. This process is highly complex and involves a sequence of interdependent and overlapping stages: hemostasis and inflammation (inflammatory phase), the formation of granulation tissue and epithelialization (proliferative phase) and the remodeling phase [4].

Skin wounds have a significant impact on public health and the investment of public resources because these wounds can lead to physical or psychosocial damage and even death [2,7]. Although there are curative treatments for chronic wounds on the market, most of these products are expensive for the patients due to the long duration of treatment. Therefore, researchers and industries have tried to explore new therapeutic strategies to accelerate the reduction of injuries [8], including the use of plants and natural products [9]. Some plant species or natural products derived from plants have been tested successfully for healing experimental wounds in recent studies $[10,11]$.

The Copaifera langsdorffii Desf. (Leguminosae), popularly known as "copaíba" is a tree that grows in the North and Northeast regions of Brazil, especially in the states of Amazonas, Pará and Ceará [12]. Since the sixteenth century, it has been used by Brazilian natives to treat various diseases [13]. Studies have demonstrated its anti-inflammatory, anti-nociceptive, antioxidant, 
antimicrobial and wound healing activities [14-18]. Most studies of gender Copaifera use the oleoresin from the bark, due to its application in folk medicine; however, there are few studies using the aerial parts of the tree [19]. Furthermore, the aromatic and phenolic compounds present in the aerial parts of Copaifera langsdorffii demonstrate its importance in the pharmaceutical and cosmetic industry [20], and the hydroalcoholic extract of the leaves is used for the treatment of urolithiasis [21]. Moreover, using the Copaifera langsdorffii leaves enables companies to obtain larger quantities of the product and lower the production costs.

Therefore, this study aims to analyze the skin wound healing activity of hydroalcoholic extract from Copaifera langsdorffii leaves in rats.

\section{Materials and Methods}

\section{Preparation of Copaifera langsdorffii hydroalcoholic extract}

Copaifera langsdorffii leaves were collected in Ribeirão Preto at the Campus of the University of São Paulo, Brazil. Plant material was identified by Professor Milton Groppo Júnior from the Biology Department of the University of São Paulo-USP, Campus Ribeirão Preto, in which a voucher specimen (SPFR 10120) was deposited. Plant material was dried in a circulating oven air drier at $40{ }^{\circ} \mathrm{C}$ for $48 \mathrm{~h}$, furnishing $250 \mathrm{~g}$ dried leaves. Plant biomass was powdered using a knife mill and submitted three times sequentially to maceration over $24 \mathrm{~h}$ using aqueous ethanol 7:3 at room temperature. After filtration, the solvent was recovered under a vacuum below $40^{\circ} \mathrm{C}$, and the crude extract was lyophilized to furnish $22 \mathrm{~g}$ hydroalcoholic extract from Copaifera langsdorffii leaves (EH).

\section{Phytochemical profile of Copaifera langsdorffii hydroalcoholic extract}

Hydroalcoholic extract of the Copaifera langsdorffii leaves was analyzed by using a Shimadzu SCL-10Avp (Kyoto, Japan) multi solvent delivery HPLC system, a Shimadzu SPD-M10Avp photodiode array detector and an Intel Celeron computer for controlling the analytical system. The analyses were undertaken using two monolithic columns linked in series (Onyx ${ }^{\mathrm{TM}} 100 \times 4.6$ $\mathrm{mm}$; C18, Phenomenex) and a pre-column from the same company. The mobile phase consisted of water (A) and acetonitrile (B). The elution program was $5-6 \%$ of phase B for 1 minute, $6-8 \%$ of $B(1-2$ minutes), $8-10 \%$ of $B$ (2-5 minutes), $10-15 \%$ of $B$ (5-12 minutes), $15 \%$ of $\mathrm{B}$ (12-22 minutes), $15-25 \%$ of B (22-27 minutes), $25 \%$ of B (27-35 minutes), $25-40 \%$ of B (35-39 minutes), $40 \%$ of B (39-42 minutes), $40-100 \%$ of $\mathrm{B}$ (42-47 minutes), $100 \%$ of $\mathrm{B}$ for 1 minute and finally an additional 12 minutes to return to the initial conditions and re-equilibrate the column. The flow rate was $1.0 \mathrm{~mL} / \mathrm{minute}$, and the detection was set at $257 \mathrm{~nm}$. HPLC-grade solvents were acquired from Tedia Company inc. (Fairfield, OH, USA). Water was purified using the Milli-Q-plus filter system (Millipore, Bedford, MA, USA). Quercetin-3-0-aL-rhamnopyranoside (quercitrin) and kaempferol-3-O-a-Lrhamnopyranoside (afzelin) were previously isolated in our laboratory, and their purities were estimated to be higher than $95 \%$ by both HPLC and NMR analyses.

\section{Animals}

Seventy-two male Wistar rats between 200 and $250 \mathrm{~g}$ were obtained from the Central Animal House of Unesp-Botucatu and were acclimated in indicidual cages at the Department of Morphology in individual cages for at least seven days before experimental manipulation, with a set temperature $\left(23 \pm 2{ }^{\circ} \mathrm{C}\right)$ and a 12-hour controlled light-dark cycle. It was provided food and water ad libitum to the animals. All the experiments were performed according to the experimental protocols (Protocol 413/12) approved by the Ethics Committee on Animal Use (CEUA/IBB/UNESP).

\section{Experimental protocol}

Skin wound excision: Rats were anesthetized with intraperitoneal ketamine $(0.08 \mathrm{mg} / 100 \mathrm{~g})$ and xylazine $(0.04 \mathrm{mg} / 100 \mathrm{~g})$. After anesthesia, the backs of the animals were shaved, and an injury was made in the dorsal region with a punch of $2 \mathrm{~cm}$ diameter. Immediately after wound induction, the topical administration of each treatment (day 1) started once a day. Subsequently, the animals were monitored for full recovery and were housed in individual cages.

\section{Treatments}

The animals were divided into four experimental groups $(\mathrm{n}=$ 6): saline; aqueous hydroalcoholic extract from the leaves at $1 \%$ $(1 \% \mathrm{EH}) ; 5 \%(5 \% \mathrm{EH})$ and $10 \%(10 \% \mathrm{EH})$. They were subjected to daily treatments with the respective solutions once a day. The aqueous hydroalcoholic extracts from Copaifera langsdorffii leaves were prepared with saline solution and the respective concentrations of the plant.

\section{Periods of treatment}

The animals were treated with daily applications of aqueous solutions during 3, 7 and 21 days, in accordance with the phases described in the literature: inflammatory, proliferative and remodeling, respectively. After each period of treatment, the animals were euthanized and samples of wound and blood were collected.

\section{Macroscopic analysis}

To determine the reduction of the wound size and the healing potential of the treatments, the limits of the edges were marked and submitted to planimetry analysis using digital pachymeter. The area of wound retraction was calculated (\%) by the following formula:

$$
\begin{aligned}
& \% \text { wound retraction }=\{(\text { initial area of the wound }- \text { area of } \\
& \text { wound measured }) / \text { initial area of the wound }\} * 100
\end{aligned}
$$

The data of the wound areas were expressed as the mean \pm SD.

\section{Histological analysis}

The samples of each animal were fixed with $4 \%$ buffered formalin and processed in paraffin for HE staining (hematoxylin 
and eosin). For HE staining, 15 pictures of slices (each slice corresponding to the respective animal) were analyzed for three different regions (normal skin, border and center of the lesion). The total number of cells present in these regions was quantified to verify the cellular differences between the regions and the tested groups, comparing the total area $\left(1.000 .000 \mu \mathrm{m}^{2}\right)$ with the labeled area of the cells $\left(\mu \mathrm{m}^{2}\right)$.

\section{Toxicity}

All animals had blood drawn and processed for biochemical analyses of systemic toxicity: AST (aspartate aminotransferase), ALT (alanine aminotransferase) and $\gamma$ GT (gamma glutamyl transferase) were used to investigate liver toxicity, and urea and creatinine were used to investigate renal toxicity.

\section{Statistical analysis}

For statistical analysis, all data were determined by analysis of variance of the repeated measures in the independent groups followed by the Newman-Keuls multiple comparison test \pm standard deviation (SD), considering a 5\% level of significance. The analyses were performed using GraphPad Prism software.

\section{Results and Discussion}

The skin consists of an important biological barrier that provides protection for vertebrates against various environmental factors. Skin lesions generate a discontinuity in that barrier and promote healing processes to reconstitute homeostasis at the injured site [22,23]. The healing process consists of different phases, including inflammation, proliferation of cells, synthesis of granulation tissue, collagen maturation and remodeling of the wound. These phases may occur overlapping and interdependently [24] and involve molecular, cellular and physiological processes to restructure the injury [23].

Plants have been used to treat various diseases and health issues for thousands of years and nearly one-third of the medicinal plants that are currently used are designed to treat skin lesions. Therefore, the use of bioactive compounds and medicinal plants is an alternative to assist in the healing process and may reduce the time of wound closure, reepithelialization and tissue fibrosis due to the presence of secondary metabolites, such as tannins, steroids, terpenoids, flavonoids, alkaloids, coumarins and saponins that act during different stages of healing [25]. The HPLC chromatographic analyses allowed the identification of two major phenolic compounds, quercetin-3-0-a-L-rhamnopyranoside (quercitrin) and kaempferol-3-0-a-L-rhamnopyranoside (afzelin) in hydroalcoholic extract of Copaifera langsdorffii leaves. Quercitrin and afzelin are glycosides of quercetin which have shown antioxidant [26], anti-inflammatory [27] activities and protection against UV-damage [28,29]. By the biological properties of these phenolic compounds, the skin wound healing capacity may be related with the presence of the two major flavonoids in the extract.

After 3 and 7 days of treatment, our study showed that EH had a tendency of injury retraction with no observable significant differences in the macroscopic analysis of the groups. Furthermore, there was the formation of a clot with exudate in all groups; however, the group treated with $10 \% \mathrm{EH}$ presented a wound with less exudate. This result correlates with the response to Glycosmis arborea extract at 5 and 10\% [24] and to the methanolic extract of Achyranthes aspera in concentrations of 2.5; 5 and 10\% [30]. After 21 days, the animals treated with all concentrations of hydroalcoholic extract of Copaifera langsdorffii leaves showed better retraction of the wounds, respectively $91.48 \%(1 \% \mathrm{EH})$, 95.18\% (5\% EH) and 95.52\% (10\% EH), compared with the saline group. Macroscopically, it was possible to observe better healing processes in the skin wounds of rats treated with $\mathrm{EH}$, with decreasing in edema of the injured area and absence of exudate and fibrin clot (Figure 1). Therefore, the macroscopic analysis demonstrated the efficacy of EH in the treatment of skin wounds, with a dose-dependent effect expressing the best results with $5 \%$ $\mathrm{EH}$ and $10 \% \mathrm{EH}$.

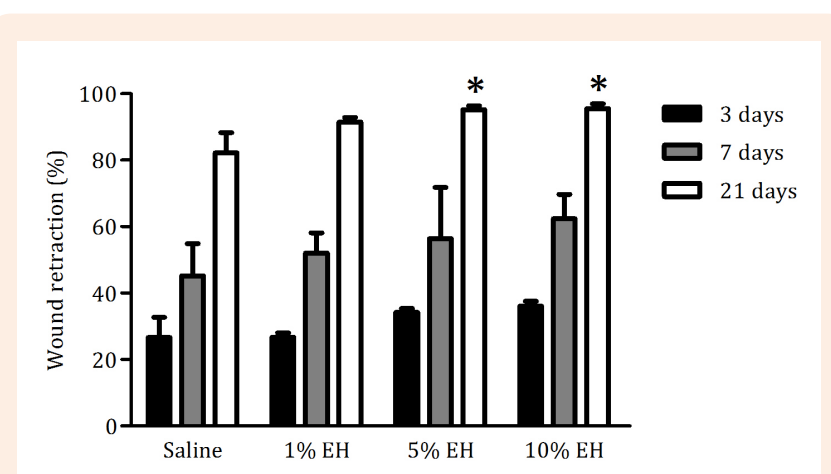

Figure 1: Percentage of skin wound retraction in animals treated with saline, $1 \% \mathrm{EH}, 5 \% \mathrm{EH}$ or $10 \% \mathrm{EH}$ during 3, 7 and 21 days. Data are presented as the average percentage of retraction (\%) and standard deviation $(n=6) .{ }^{*} \mathrm{p}<0.05$ compared with saline.

The disruption of skin integrity promotes the increase of inflammatory mediators, which are vital to tissue healing and repair [31]. Neutrophils and macrophages are important both to prevent the spread of an infection to other areas of the body and in regulating the temporal progression between the stages of wound healing. Furthermore, the proliferation and migration of different cellular types of the region started simultaneously the inflammation [32]. During the 3 days of treatment with the hydroalcoholic extract from Copaifera langsdorffii, we observed an increase in the number of total cells of the regions from the border and center of the wounds of groups $1 \% \mathrm{EH}$ and $10 \% \mathrm{EH}$ compared with the saline group, thus determining an initial process of healing response through migration and proliferation of the cells presented in the area (Figures 2 \& 3). After 7 days, the migration and proliferation are the main mechanisms of the skin wound healing of the cells of the wound, with the reepithelialization and synthesis of granulation tissue. Although our treatments increase the number of cells in 3 days, with stimulus to proliferation and migration of cells compared with the negative control, after 7 days, there was the physiological progression of wound healing and we did not observe any difference between the cellularity of the groups (Figures $2 \& 4$ ). After 21 days, corresponding to the last stage of wound healing, we observed a decrease in cellularity around the wound edges of the groups $5 \% \mathrm{EH}$ and $10 \% \mathrm{EH}$, which 
is characterizing the reduction of proliferation and anticipating the remodeling mechanism compared with saline and 1\% EH groups (Figures 2 \& 5).

To verify the possible toxic effects from treatments with Copaifera langsdorffii, biochemical analyses of liver and kidney toxicity were made using patterns of AST (U/L), ALT $(\mathrm{U} / \mathrm{L}), \gamma$ GT $(\mathrm{U} / \mathrm{L})$, urea $(\mathrm{mg} / \mathrm{dL})$ and creatinine $(\mathrm{mg} / \mathrm{dL})$. The data demonstrated that there were no toxic effects from any concentration of the hydroalcoholic extract of Copaifera langsdorffii after 3,7 or 21 days (Table 1).

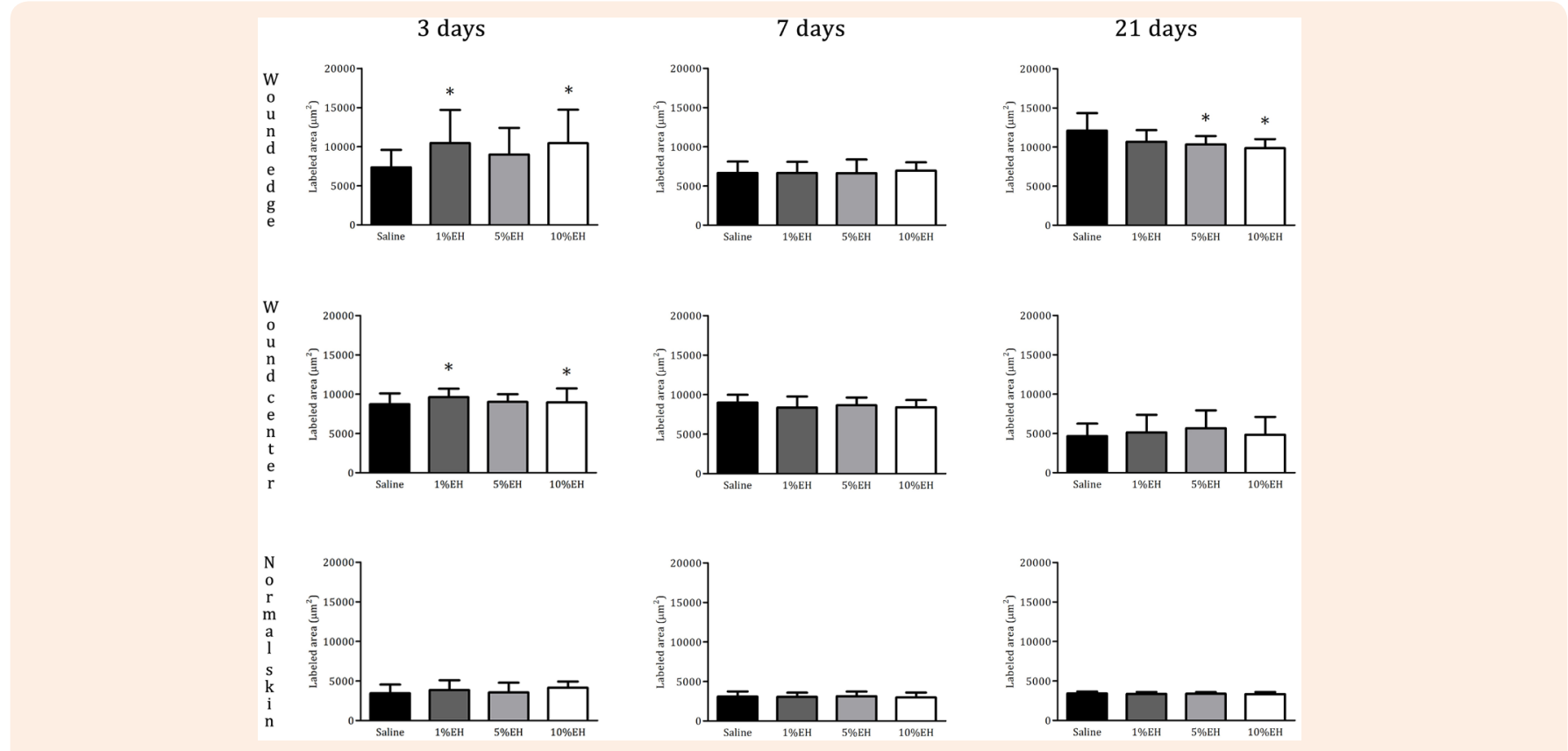

Figure 2: Quantification of total cells (labeled area $\mu \mathrm{m}^{2}$ ) in the region of skin around the wound edges, wound center and normal skin from rats treated with EH after 3,7 and 21 days. ${ }^{*}$ p $<0.05$ compared with saline.

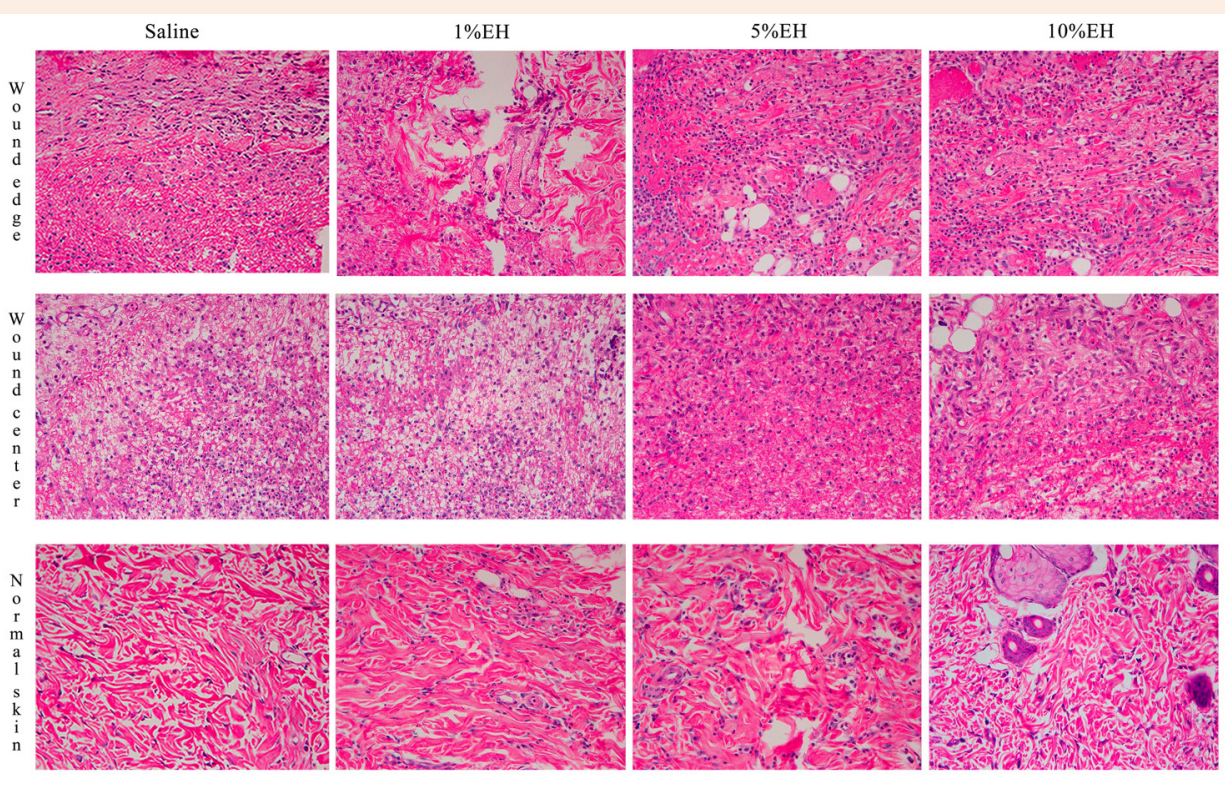

Figure 3: Photomicrograph of skin around the wound edges, wound center and normal skin from rats after 3 days of treatment with EH. 


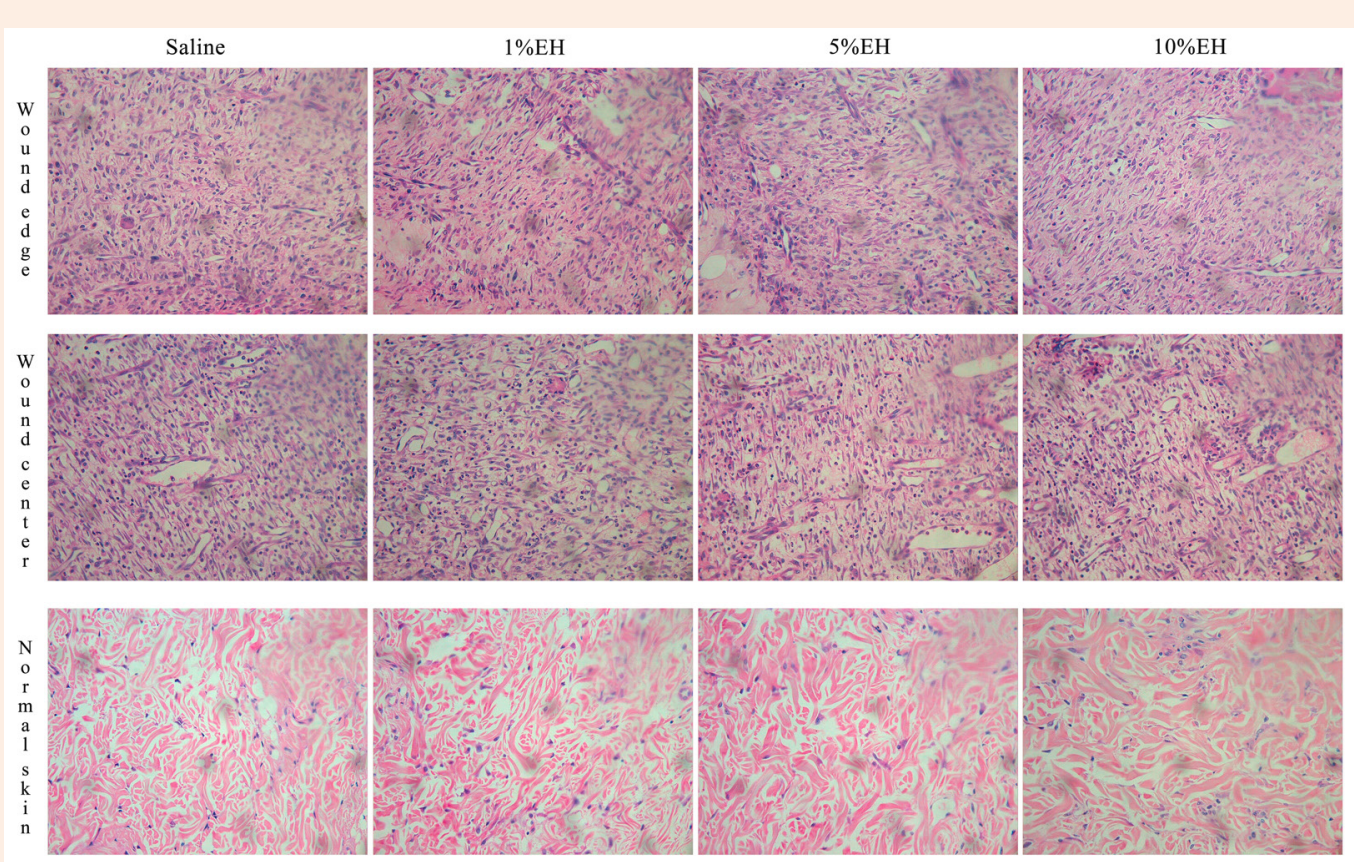

Figure 4: Photomicrograph of skin around the wound edges, wound center and normal skin from rats after 7 days of treatment with EH.

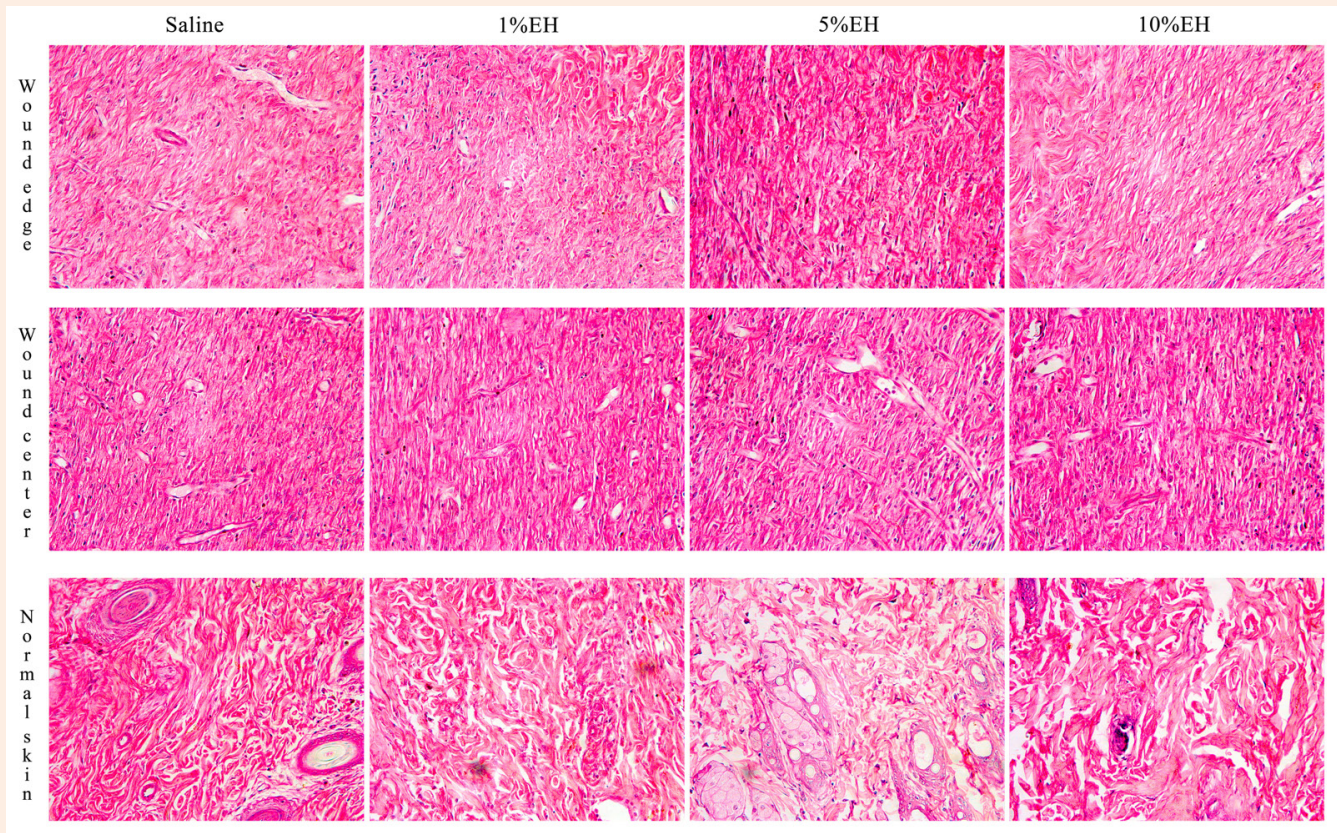

Figure 5: Photomicrograph of skin around the wound edges, wound center and normal skin from rats after 21 days of treatment with EH. 
Table 1: Toxicity analysis of rats blood after being treated with hydroalcoholic extract from Copaifera langsdorffii for 3,7 and 21 days.

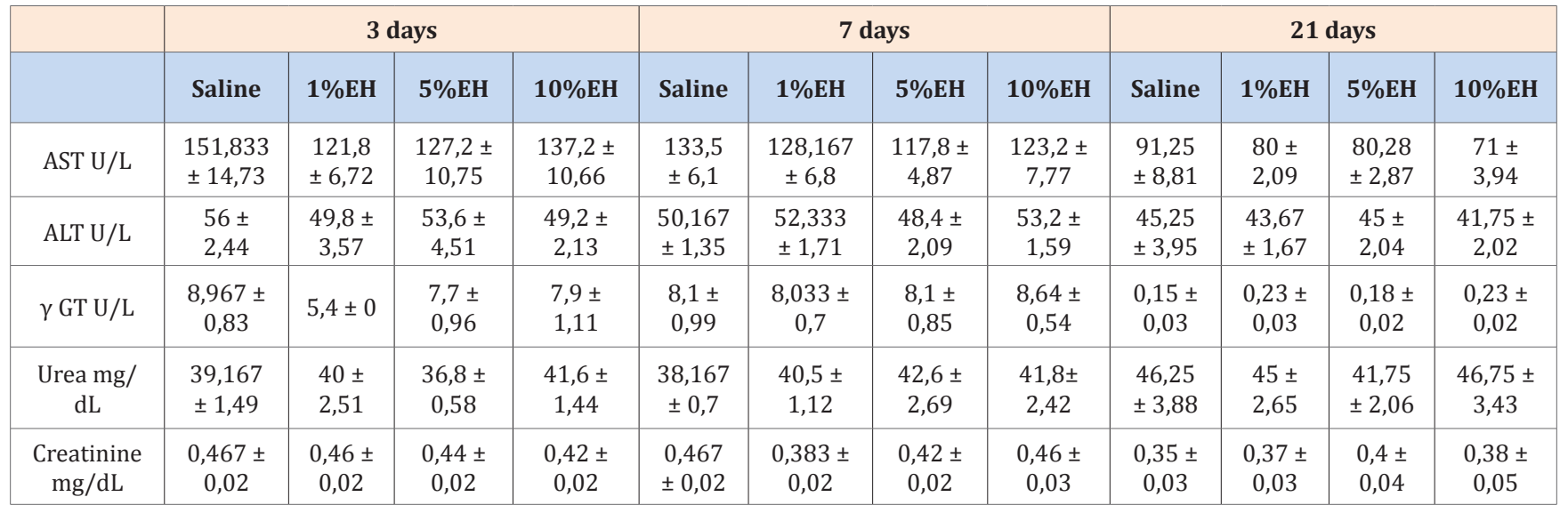

ALT: alanine aminotransferase

$\gamma$ GT: $\gamma$ glutamyl transferase

AST: aspartate aminotransferase

\section{Conclusion}

In this study, we presented a new alternative to the treatment of skin wound using Copaifera langsdorffii, considering the popular use of oleoresin. The hydroalcoholic extract from Copaifera langsdorffii leaves showed a positive effect on skin wound healing. Microscopic analysis showed anticipation of proliferative and migration mechanisms in the groups treated with EH compared with the saline group. Macroscopic analysis demonstrated wound retraction after 21 days in groups 5\% $\mathrm{EH}$ and 10\% EH compared with saline group, with reduction of edema and exudate of the wounds. These data showed the modulatory effect of EH, with better wound closure effects seen following treatment with $10 \%$ $\mathrm{EH}$ that started at the microscopic level after 3 days and were observed macroscopically after 21 days. Furthermore, there was no toxicity according to our data, showing the efficacy and safety of the treatment.

\section{Acknowledgment}

This research was supported by FAPESP (Fundação de Amparo à Pesquisa do Estado de São Paulo) 2012/15092-5 and 2011/13630-7. The authors thank VM Souza, FJ Fontana and MRR Sarzi for their technical support (Laboratório de Histologia UNIPEX, FMB/Unesp).

\section{References}

1. Evans ND, Oreffo ROC, Healy E, Thurner PJ, Man YH (2013) Epithelia mechanobiology, skin wound healing, and the stem cell niche. J Mech Behav Biomed Mater 28: 397-409.

2. Guo S, Dipietro LA (2010) Factors affecting wound healing. J Dent Res 89(3): 219-229.

3. De Benedetto A, Kubo A, Beck LA (2012) Skin barrier disruption: a requirement for allergen sensitization? J Invest Dermatol 132(3): 949-963.

4. Morin C, Roumegous A, Carpentier G, Barbier-Chassefière B, GarrigueAntar L, et al. (2012) Modulation of inflammation by Cicaderma ointment accelerates skin wound healing. J Pharmacol Exp Ther 343(1): 115-124.
5. Mandelbaum SH, Di Santis ÉP, Mandelbaum MHS (2003) Cicatrização: conceitos atuais e recursos auxiliares - Parte I. An Bras Dermatol 78(4): 393-408.

6. Balbino CA, Pereira LM, Curi R (2005) Mecanismos envolvidos na cicatrização : uma revisão. Rev Bras Ciências Farm 41: 27-51.

7. Bayat A, Mcgrouther DA, Ferguson MWJ (2003) Skin scarring. BM] 326(7380): 88-92.

8. Rennert RC, Rodrigues M, Wong VW, Duscher D, Hu M, et al. (2013) Biological therapies for the treatment of cutaneous wounds: phase III and launched therapies. Expert Opin Biol Ther 13(11): 1523-1541.

9. Gál P, Toporcer T, Grendel T, Vidová Z, Smetana K, et al. (2009) Effect of Atropa belladonna L. on skin wound healing: biomechanical and histological study in rats and in vitro study in keratinocytes, 3T3 fibroblasts, and human umbilical vein endothelial cells. Wound Repair Regen 17(3): 378-386.

10. Cetin EO, Yesil-Celiktas O, Cavusoglu T, Demirel-Sezer E, Akdemir O, et al. (2013) Incision wound healing activity of pine bark extract containing topical formulations: a study with histopathological and biochemical analyses in albino rats. Pharmazie 68(1): 75-80.

11. Upadhyay A, Chattopadhyay P, Goyary D, Mazumder PM, Veer V (2013) Eleutherine indica L. accelerates in vivo cutaneous wound healing by stimulating Smad-mediated collagen production. J Ethnopharmacol 146(2): 490-494.

12. Paiva LAF, Cunha KMDA, Santos FA, Gramosa NV, Silveira ER, et al. (2002) Investigation on the wound healing activity of oleo-resin from Copaifera langsdorffi in rats. Phytother Res 16(8): 737-739.

13. Veiga Junior VF, Pinto AC (2002) O Gênero Copaifera L. Quim Nov 25(2): 273-286.

14. Basile A, Sertie J, Freitas P, Zanini A (1988) Anti-inflammatory activity of oleoresin from Brazilian Copaifera. J Ethnopharmacol 22(1): 101109.

15. Carvalho JCT, Cascon V, Possebon LS, Morimoto MSS, Cardoso LGV, et al. (2005) Topical anti-inflammatory and analgesic activities of Copaifera duckei dwyer. Phytother Res 19(11): 946-950.

16. Gomes NM, Rezende CM, Fontes SP, Matheus ME, Fernandes PD (2007) Antinociceptive activity of Amazonian Copaiba oils. J Ethnopharmacol 109(3): 486-492. 
17. Paiva LAF, Gurgel LA, Campos AR, Silveira ER, Rao VSN (2004) Attenuation of ischemia/reperfusion-induced intestinal injury by oleo-resin from Copaifera langsdorffii in rats. Life Sci 75(16): 19791987.

18. Kang R, Helms R, Stout MJ, Jaber H, Chen Z, Nakatsu T (1992) Antimicrobial activity of the volatile constituents of Perilla frutescens and its synergistic effects with polygodial. J Agric Food Chem 40(11): 2328-2330.

19. Alves JM, Munari CC, Monteiro Neto MAB, Furtado RA, Senedese JM, et al. (2013) In vivo protective effect of Copaifera langsdorffii hydroalcoholic extract on micronuclei induction by doxorubicin. J Appl Toxicol 33(8): 854-860.

20. Stupp T, Freitas RA, Sierakowski MR, Deschamps FC, Wisniewski A, et al. (2008) Characterization and potential uses of Copaifera langsdorfii seeds and seed oil. Bioresour Technol 99(7): 2659-2663.

21. Sousa JPB, Brancalion APS, Souza AB, Turatti ICC, Ambrósio SR, et al. (2011) Validation of a gas chromatographic method to quantify sesquiterpenes in copaiba oils. J Pharm Biomed Anal 54(4): 653-659.

22. Proksch E, Brandner JM, Jensen JM (2008) The skin: an indispensable barrier. Exp Dermatol 17(12): 1063-1072.

23. Jin G, Prabhakaran MP, Kai D, Annamalai SK, Arunachalam KD, et al. (2013) Tissue engineered plant extracts as nanofibrous wound dressing. Biomaterials 34(3): 724-734.

24. Silambujanaki P, Chandra CBT, Anil Kumar K, Chitra V (2011) Wound healing activity of Glycosmis arborea leaf extract in rats. J Ethnopharmacol 134(1): 198-201.
25. Thomé RG, dos Santos HB, dos Santos FV, da Silva Oliveira RI de Camargos LF, et al. (2012) Evaluation of healing wound and genotoxicity potentials from extracts hydroalcoholic of Plantago major and Siparuna guianensis. Exp Biol Med 237(12): 1379-1386.

26. Babujanarthanam R, Pandian MR (2011) Quercitrin a bioflavonoid improves the antioxidant status in streptozotocin: induced diabetic rat tissues. Mol Cell Biochem 358(1-2): 121-129.

27. Truong V, Ko S, Jun M, Jeong W (2016) Toxicity in HepG2 Cells and Mice through Induction of Antioxidant Machinery and Mice through Induction of Antioxidant Machinery and Inhibition of Inflammation. Nutrients 8(7): 1-16

28. Yin Y, Li W, Son Y, Sun L, Lu J, et al. (2014) Quercitrin Protects Skin from UVB-induced Oxidative Damage. Toxicol Appl Pharmacol 269(2): 89-99.

29. Shin SW, Jung E, Kim S, Kim J, Kim E, et al. (2013) Antagonizing Effects and Mechanisms of Afzelin against UVB-Induced Cell Damage. PLoS One 8(4): e61971.

30. Fikru A, Makonnen E, Eguale T, Debella A, Mekonnen GA (2012) Evaluation of in vivo wound healing activity of methanol extract of Achyranthes aspera L. J Ethnopharmacol 143(2): 469-474.

31. Midwood KS, Williams LV, Schwarzbauer JE (2004) Tissue repair and the dynamics of the extracellular matrix. Int J Biochem Cell Biol 36(6): 1031-1037.

32. Dovi JV, He L, Dipietro LA (2002) Accelerated wound closure in neutrophil-depleted mice. J. Leuk Biol 73(4): 448-455. 